JIKAP PGSD: Jurnal Ilmiah Ilmu Kependidikan

Vol, 4. No,1. Tahun 2020

e-ISSN: 2597-4440 dan p-ISSN: 2597-4424

This work is licensed under a Creative Commons Attribution

4.0 International License

\title{
Implementasi Kepemimpinan Sekolah Terhadap Pendidikan Karakter Di SD Islam Al-Azhar 34 Makassar
}

\author{
Nurul Fadhilah ${ }^{1}$, Rosleny Babo ${ }^{2}$, M Basri $^{3}$ \\ ${ }^{1}$ Pendidikan Dasar Program PascasarjanaUniversitas Muhammadiyah Makassar \\ ${ }^{2,3}$ Universitas Muhammadiyah Makassar \\ Email: ${ }^{1}$ dhilarasyid@gmail.com \\ ${ }^{2}$ Rosleny.babo@gmail.com \\ 3basri.ppkhb@yahoo.com
}

\begin{abstract}
Abstrak. Berlandaskan survey yang telah dilakukan oleh peneliti di SD Islam Al-Azhar 34 Makassar yaitu masih adanya sebagian perilaku peserta didik yang tidak mencerminkan karakter sebagai siswa di sekolah Islam seperti : berbicara kasar terhadap gurunya, tidak menghormati orang yang lebih tua, school bulliying, menyontek dan membohongi orangtua dan guru. Penelitian ini bertujuan untuk mengetahui pelaksanaan dan kebijakan kepemimpinan di Sekolah dalam penerapan pendidikan karakter di SD Islam Al-Azhar 34 Makassar, serta faktor pendukung dan penghambat implementasi pendidikan karakter. Penelitian ini merupakan penelitian kualitatif. Jumlah informan sebanyak 8 orang. Teknik pengumpulan data dengan cara observasi, wawancara, dan dokumentasi. Hasil penelitian adalah pemimpin sekolah yang terdiri dari kepala sekolah, wakil kepala sekolah, komite sekolah dan guru telah membuat program dan kegiatan sekolah berupa pembiasaan dan budaya sekolah yang berkaitan dengan nilai religius, jujur, disiplin, dan tanggung jawab.
\end{abstract}

Kata kunci: Implementasi Kepemimpinan, kepemimpinan sekolah, Pendidikkan Karakter.

\begin{abstract}
Based on a survey conducted by researchers at SD Al-Azbar 34 Makassar, namely the persistence of some of the behavior of students who do not reflect the character as a student in an Islamic school such as: speaking harshly to their teachers, not respecting older people, school bullies cheating and lying to parents and teachers. This study aims to determine the implementation and leadership policies in schools in the application of character education in SD Al-Azhar 34 Makassar, as well as supporting and inhibiting factors for the implementation of character education. This research is a qualitative research. There were 8 informants. Data collection techniques by observation, interview, and documentation. The results of the study are school leaders consisting of school principals, deputy principals, school committees and teachers who have made school programs and activities in the form of school habits and culture related to religious values, honesty, discipline, and responsibility.
\end{abstract}

Keyword: Leadership Implementation, School Leadership, Character Building

\section{PENDAHULUAN}

Kurikukulum merupakan hal yang sangat penting dalam menunjang jalannya pendidikan di Indonesia, oleh karena itu kurikulum setiap tahunnya harus dievaluasi sehingga dapat mewujudkan tujuan pendidikan nasional dengan memperhatikan tahap perkembangan peserta didik dan kesesuaiannya 
dengan lingkungan.

Pengembangan kurikulum tersebut disebabkan dengan melihat tahap perkembangan peserta didik dan kesesuaiannya dengan lingkungan yang dibutuhkan pada saat sekarang. kurikulum 2013 atau yang lebih sering disebut dengan K.13 ini lebih menekankan kepada karakter siswa dan diharapkan dapat membantu dalam pelaksanaan pendidikan di sekolah untuk menciptakan anak didik yang berkarakter.

Banyaknya perilaku menyimpang di masyarakat yang disebabkan oleh peserta didik seperti tawuran, begal, tidak menghormati orang yang lebih tua. Ini merupakan tamparan keras bagi dunia pendidikan, belum lagi kejadian yang terjadi di salah satu pondok pesantren mengenai temannya yang sama-sama masih di bawah umur (Patroli Indosiar, Rabu 11/4/2018).

Kebanyakan orangtua sekarang lebih memilih menyekolahkan anaknya di sekolah yang lebih banyak belajar tentang ilmu agama seperti di Pesantren, Madrasah, dan Sekolah Islam Terpadu (SIT) dibandingkan di sekolah umum, hal tersebut belum tentu menjamin seorang anak dapat berperilaku baik sehingga itu dapat menjadi salah satu dasar yang perlu di pikirkan kembali oleh orangtua sebelum memasukkan anaknya ke suatu sekolah baik itu sekolah umum atau boardingschool, seperti kejadian di atas didalam pesantren saja bisa terjadi hal yang sangat memprihatinkan.

Banyaknya permasalahan yang dialami oleh para pelajar menjadi tugas berat yang harus segera dikerjakan oleh pemerintah, maka dari itu pemerintah berusaha memperbaiki proses dunia pendidikan dengan cara mengintegrasikan nilai-nilai karakter ke dalam pembelajaran menggunakan K.13 melalui pembiasaan. Banyaknya usaha yang dilakukan oleh pemerintah dalam menciptakan pendidikan yang baik itu masih dipengaruhi kuat oleh pelaksananya di lapangan.

Jasruddin (30 April 2018) menjelaskan dalam seminar pendidikan bahwa karakter itu tidak untuk diajarkan, akan tetapi di contohkan sebagaimana yang dilakukan oleh Rasulullah SAW dalam menanamkan dan menumbuhkan karakter terhadap para sahabat yakni dengan mencontohkan kebaikan-kebaikan. Penelitian terdahulu yang dilakukan oleh Ahmad Suriansyah dan Aslamiah (2015) pada hasil penelitian ini menunjukkan bahwa yang berperan penting dalam pembentukan karakter seorang peserta didik adalah strategi yang dilakukan oleh kepemimpinan kepala sekolah, guru, dan orangtua dalam menanamkan perilaku karakter, hal tersebut dikarenakan merekalah yang bersentuhan langsung dengan peserta didik di sekolah.

Sejalan dengan penelitian di atas, adapun penelitian terdahulu yang telah dilakukan oleh (Murniati et.al, 2016) dengan judul "Strategi Kepala Sekolah dalam Implementasi Pendidikan Karakter Pada Sekolah Menengah Atas Negeri 1 Julok". Pada penelitiannya ini bertujuan untuk mengetahui upaya apa saja yang dilakukan oleh kepala sekolah dalam implementasi pendidikan karakter pada SMA Negeri 1 Julok. Penelitian ini menggunakan pendekatan kualitatif dengan metode deskriktif dengan hasil penelitian menunjukkan kepala sekolah telah menyususun program dalam mengimplementasi pendidikan karakter dengan cara mewajibkan setiap guru bidang studi untuk membuat perangkat pembelajaran sesuai dengan kurikulum yang terbaru, menyesuaikan perkembangan buku pengangan guru bidang studi.

Pemimpin sekolah yang memiliki peran besar adalah kepala sekolah karena dialah yang dapat mengayomi semua stakeholder maka dari itu, menurut Okoji dalam Kadir (2019) untuk menjadi pemimpin yang sukses, seorang kepala sekolah harus mengidentifikasi aspek-aspek yang berbeda dari perannya sebagai pemimpin, tantangan pertama mereka adalah mengarahkan kembali kepemimpinan dari manajemen ke kepemimpinan, Sebagai pemimpin di sekolah, kepala sekolah merupakan individu yang dituntut mampu melakukan transformasi kemampuannya melalui bimbingan, tuntunan dan pemberdayaan kepada seluruh warga sekolah (Purwanti, et.al, 2014: 391)

Adanya strategi yang dilakukan oleh Kepemimpinan di sekolah diharapkan dapat membantu terlaksananya pembentukan karakter bagi peserta didik karena pendidikan karakter yang diterapkan tidak diajarkan dalam mata pelajaran khusus tetapi diajarkan dengan cara praktek yang dilaksanakan melalui keseharian siswa tersebut di sekolah, Membicarakan peranan kepemimpinan sekolah telah ada berbagai teori atau pendekatan seperti: teori sifat, teori perilaku, dan kontingensi.

Berlandaskan pra survey yang telah dilakukan oleh peneliti pada tanggal 20 Agustus 2018 di SD Islam Al-Azhar 34 Makassar yaitu masih adanya sebagian perilaku peserta didik yang tidak mencerminkan karakter sebagai siswa di sekolah Islam seperti : berbicara kasar 
terhadap gurunya, tidak menghormati orang yang lebih tua, school bulliying, menyontek dan membohongi orangtua dan guru. Dengan adanya permasalahan tersebut maka diperlukan peran pemimpin sekolah antara lain kepala sekolah, wakil kepala sekolah, komite sekolah dan guru terhadap pemahaman penerapan pendidikan karakter serta perannya dalam menguasai praktik manajemen sekolah yang berpihak pada praktik pendidikan karakter, sehingga dapat membantu peserta didik dalam pembentukan karakternya. Oleh karena itu, peneliti bermaksud untuk melakukan penelitian dengan mengusulkan "Implementasi Kepemimpinan Sekolah terhadap Pendidikan Karakter di SD Islam Al-Azhar 34 Makassar" sebagai judul dalam penelitian ini.

\section{METODE PENELITIAN}

Pendekatan yang dilakukan dalam penilitian ini adalah kualitaif penulis mengambil penelitian kualitatif dengan alasan penelitian dilakukan pada objek yang alamiah. Menurut Lincoln dan Guba dalam (Moleong, 2017) objek yang alamiah adalah penelitian yang diharapkan adanya kenyataan-kenyataan sebagai keutuhan yang tidak dapat dipahami jika dipisahkan. Objek alamiah yang dapat diartikan bahwa berkembang apa adanya, tidak dimanipulasi oleh peneliti dan kehadiran peneliti tidak mempengaruhi dinamika pada objek tersebut.

Menurut Arikunto (2013:3) pendekatan deskriptif adalah penelitian yang dimaksudkan untuk menyelidiki keadaan, kondisi atau hal lain-lain yang sudah disebutkan, yang hasilnya dipaparkan dalam bentuk laporan penelitian atau lisan dari orang-orang dan perilaku yang dapat diamati. Penelitian ini menggunakan berbagai sumber bukti (yang bisa jadi kualitatif, kuantitatif atau kedua-duanya) terhadap satu entitas tunggal yang dibatasi oleh ruang dan waktu, pada umumnya studi kasus dihubungkan dengan sebuah lokasi "kasusnya" (Christine Daymon, 2008).

Penelitian dilaksanakan di SD Islam Al-Azhar 34 Makassar berlokasi di Kecamatan Rappocini Kota Makassar. Penelitian dilakukan pada bulan Desember 2017 sampai dengan Januari 2018 di Kecamatan Rappocini.

Data yang diperoleh atau dikumpulkan langsung di lapangan oleh peneliti. Sumber data primer pada penlitian ini adalah wawancara dan observasi pada semua komponen sekolah yang ada kaitannya dengan pelaksanaan, perencanaan dan evaluasi pendidikan karakter. Data primer diperoleh dari informan kunci (pemimpin sekolah) dengan kriteria tertentu yang di tetapkan peneliiti yang sesuai dengan fokus masalah dalam penelitian ini. data sekunder adalah penelitian ini berupa dokumen sekolah, kebijakan-kebijakan sekolah yang berkaitan dalam penerapan pendidikan karakter dan lainnya yang terkait dengan penelitian ini. Teknik pengumpulan data dengan cara: wawancara mendalam, observasi, dokumentasi dan triangulasi.

\section{HASIL DAN PEMBAHASAN}

Wawancara dilakukan pertama pada kepala sekolah terkait pelaksanaan pendidikan karakter di sekolah, peran pemimpin dan strategi yang dilakukan dalam penanaman nilai karakter. Wawancara selanjutnya dilakukan pada para wakasek terkait dengan strategi dan program yang digunakan dalam menumbuhkan nilai karakter peserta didik. Ketiga, guru terkait bagaimana pelaksanaan penerapan atau penanaman pendidikan karakter dalam pembelajaran, keempat komite sekolah (jamiyah) terkait peran dalam pelaksanaan pendidikan karakter di sekolah dan terakhir wawancara kepada peserta didik untuk mengetahui bagaimana strategi guru dalam menumbuhkan nilai karakternya. Dokumentasi, menjadi data yang mendukung peneliti pada saat penilitian yang menghimpun data-data kondisi fisik sekolah, letak sekolah, sarana prasarana, keadaan kepala sekolah, keadaan wakasek, keadaan komite sekolah, keadaan guru, keadaan peserta didik, RPP guru, dan hasil tentang nilai karakter peserta didik. Setelah didapat hasil observasi, wawancara dan dokumentasi.

Hasil wawancara yang dilakukan dengan bapak Jamalullaili, S.Pd.I selaku kepala sekolah yang menyatakan bahwa: "Menurut saya sebagai kepala sekolah, mengenai perlu atau tidaknya pendidikan karakter di sekolah yaitu sekolah sangat memerlukan program pendidikan karakter karena pendidikan karakter merupakan cikal bakal dalam menumbuhkan akhlak kepribadian yang baik bagi peserta didik. Upaya saya sebagai kepala sekolah dalam melaksanakan program pendidikan karakter yaitu dengan memberikan tugas masing-masing kepada pemimpin sekolah lainnya dalam membuat program yang dapat mendukung dan mengembangkan pendidikan karakter peserta didik dengan melakukan berbagai kesiapan seperti mendukung berbagai program atau kegiatan yang direncanakan oleh pemimpin sekolah. Tata tertib dan visi misi juga dibuat dengan keterlibatan berbagai pemimpin 
sekolah seperti wakasek,guru, komite dan seluruh warga sekolah yang berwewenang, penerapan tata tertib dan visi misi sekolah yang berlandaskan pendidikan karakter dilaksanakan dengan cara pembiasaan dan pemberian sanksi bagi yang melanggar.

Hal serupa juga diungkapkan oleh para pemimpin sekolah seperti wakasek, guru dan komite di SDI Al-Azhar 34 Makassar kepada peneliti, yaitu sebagai "Para wakasek, guru dan komite juga terlibat dalam pembuatan tata tertib dan visi misi sekolah karena untuk membuat tata tertib dan visi misi harus sesuai dengan kondisi yang terjadi di sekolah dan karakter apa yang akan dibangun di sekolah tersebut. Dengan terlibatnya semua pemimpin sekolah maka mereka bersama-sama memiliki peran penting dalam menerapkan dengan cara pembiasaan, karena membangun suatu karakter itu harus dengan pembiasaan yang dikerjakan secara berulang-ulang sehingga menciptakan karakter yang sesuai dengan harapan.

Pengimplementasian kepemimpinan sekolah terhadap pendidikan karakter peserta didik di SD islam al-azhar 34 makassar, dikuatkan dengan hasil observasi yang dilakukan oleh peneliti. Adapun hasil observasi peneliti adalah sebagi berikut : Pada tanggal 4 April 2019, peneliti mengamati bahwa guru-guru di SD islam al-azhar 34 makassar hadir lebih awal untuk menjemput para peserta didik. Guru-guru hadir sebelum pukul 06.45. Para peserta didik hadir sebelum pukul 07.00. karena pukul 07.15 07.30 peserta didik diharuskan untuk masuk ruang kelas membaca dan menghafalkan surah-surah pendek. Setelah itu, peneliti melihat dan mengamati pada pukul 07.30-08.00 melaksanakan ikrar dan doa pagi bersama yang dilanjutkan dengan shalat duha' secara berjamaah.

Senada dengan apa yang dipaparkan oleh para pemimpin sekolah, diperkuat oleh peserta didik yang bernama Annisa Nurfadilla Adelia, ia menuturkan bahwa: "Tata tertib yang ada di sekolah itu banyak, dan kami harus mengikuti semua tata tertib yang di sekolah. Tata tertib yang saya ingat itu ada menjaga skala suara, datang tidak boleh terlambat, izin ke guru jika ingin meninggalkan kelas, berjalan dengan tertib di selasar, naik dan turun tangga di sebelah kiri dan masih banyak lagi. Tata tertib yang paling sering saya langgar itu skala suara, saya belum bisa menjaga skala suara karena saya masih sering teriak-teriak ketika berbicara sama teman dan juga berlari ketika jalan. Ketika saya melanggar dan didapati guru maka saya akan ditegur dan menapatkan sanksi, sanksi yang paling sering saya dapatkan itu biasanya disuruh istighfar sebanyak 100 kali atau jika kami terlambat datang ke sekolah maka kami disuruh berikrar di lapangan dan kalau pelanggaran kami banyak dan parah maka kami akan disuruh ke BK dan dibimbing disana. Kalau soal visi misi saya tidak tahu isinya semua apa tapi saya biasa membacanya ketika naik di lantai dua karena disana dipasang papan yang berisi tulisan visi misi sekolah yang saya ingat itu salah satu visi misinya berbunyi Mengembangkan kebiasan hidup yang islami, sehat, bersih, dan peduli sosial. menurut saya, saya sudah melaksanakan sebagian visi misi sekolah salah satunya itu mengembangkan kebiasaan hidup islami Alhamdulillah saya sudah mulai terbiasa sholat walaupun ada bolong-bolongnya".

Berdasarkan wawancara yang telah dilaksanakan maka dapat diketahui bahwa banyaknya program yang diterapkan sekolah dalam mengembangkan pendidikan karakter antara lain: a) Guru menjemput peserta didik di pagi hari di depan gerbang sekolah; b) Setiap guru memiliki tugas piket untuk mengawasi setiap kegiatan siswa pada saat baru datagng ke sekolah, istirahat dan pada saat jam kepulangan; c) Sebelum belajar siswa wajib tadarrus dan menghafal surah-surah pendek, berikrar, doa pagi dan melaksanakan sholat dhuha; d) Peserta didik difasilitasi dengan masjid yang besar dan wajib melaksanakan sholat dzuhur secara berjamaah bagi kelas tinggi $(4,5,6)$; e) Peserta didik diberikan ekskul pengembangan diri dalam bidang keagamaan seperti mengaji dan tahfiz; f) Ekskul kepramukaan yang dilasanakan oleh kelas tinggi; g) Dilaksanakanya malam bina ilmu dan takwa (mabit); h) Siswa diberikan hafalan surah-surah pendek dan wajib menghafal juz 30 ; i) Adanya buku akhlakul karimah yang diberikan kepada siswa sebagai sarana untuk mengontrol sholat dan perilaku apa yang dilakukan di rumah dan wajib untuk diisi oleh orangtu orangtua dan dicek oleh guru.

Kesembilan program tersebut masih banyak lagi program dan aturan yang diterapkan yang dapat mendukung terlaksananya pendidikan karakter di sekolah tersebut. Dalam mewujudkan program tersebut, tentulah pemimpin sekolah memiliki perencanaan dalam mengaplikasikannya. Perencanaan yang digagas oleh kepala sekolah dan seluruh pemimpin sekolah sehinnga strategi yang 
direncanakan menjadi pembiasaan oleh peserta didik hingga melekat menjadi karakter.

Pembiasaan menyambut peserta didik di pagi hari memberikan banyak manfaat dan sejalan dengan program pemerintah dalam memberikan penguatan pendidikan karakter. Selain disiplin,hal yang diperoleh adalah berkesempatan mengenal orangtua peserta didik.

\section{SIMPULAN DAN SARAN}

Implementasi kepemimpinan di sekolah sangat berpengaruh dalam penerapan pendidikan karakter, oleh karena itu stakeholder yang berada di sekolah harus mempunyai jiwa kepemimpinan yang dapat memberikan sebuah perubahan sesuai dengan harapan yang ingin dibentuk. Adanya peran pemimpin sekolah dapat memberikan perubahan dengan memberikan program-program maupun peraturan di sekolah yang dapat membentuk karakter peserta didik. Pendidikan karakter dapat dilaksanakan dengan adanya pembiasaan yang dikerjakan secara berulang-ulang di sekolah, di rumah maupun di lingkungan peserta didik dengan adanya kerja sama antar stakeholder dan orangtua peserta didik.

Adapun saran dari peneliti yaitu harus adanya kerjasama dengan setiap unsur sekolah dengan orangtua siswa yang ada agar program pembinaan karakter siswa dapat terealisasi dengan nyata dan lancar. Selanjutnya untuk pemimpin sekolah agar memperhatikan kebijakan yang diputuskan agar tidak ada program yang yang ketinggalan dalam implementasinya.

\section{DAFTAR RUJUKAN}

Arikunto. 2013. Prosedur Peneliian : Suatu Pendekatan Praktik. Jakarta : Rineka Cipta

Arifin, Imron. 2016. Kepemimpinan pembelajaran kepala sekolah dalam menerapkan pendidikan karakter pada era masyarakat ekonomi asean. Jurnal Pendidikan Universitas Negeri Malang, Fakultas Pendidikan dan Keguruan

Jasruddin. 2018. Revolusi Pendidikan Era Milenial 4.0. Makalah Disajikan dalam Seminar Pendidikan. Universitas Muhammadiyah Makassar. Makassar. 30 April.

Kadir \& Mulyadi. 2019. Pengaruh Kepemimpinan Kepala Sekolah, Sarana Prasarana, dan Motivasi Kerja Guru Terhadap Kinerja Guru SMA. Jurnal
Ilmu Pendidikan, Keguruan, dan Pembelajaran, 3(2)

Komariah, Nur \& Rohana. 2016. Peran Wakil Kepala Sekolah Bidang Kesiswaan Dalam Meningkatkan Disiplin Siswa Di Sekolah Menengah Atas (Sma) Muhammadiyah Tembilahan. (ejournal.fiaiunisi.ac.id/index.php/al-afk ar/article/download/105/101) diakses tanggal 20 Mei 2018.

Ramdani, Muhammad Ali. 2014. Lingkungan pendidikan dalam implementasi pendidikan karakter. Jurnal Pendidikan Universitas Garut, Fakultas Pendidikan Islam dan Keguruan Universitas Garut ISSN: 1907-932X

Moleong, Lexy. 2017. Metodologi Penelitian Kualitatif Edisi Revisi. Bandung: PT Remaja Rosdakarya.

Mulyadi. 2010. Kepemimpinan Kepala Sekolah Dalam Mengembangkan Budaya Mutu. Cetakan pertama. Malang: UIN Maliki Press.

Murniati, A.R. 2016. Strategi Kepala Sekolah Dalam Implementasi Pendidikan Karakter Pada Sekolah Menengah Atas Negeri 1 Julok. Jurnal Administrasi Pendidikan: 4 (1).

Purwanti, K., Murniati, A.R. dan Yusrizal. 2014. Kepemimpinan Kepala Sekolah Dalam Meningkatkan Kompetensi Guru Pada SMP Negeri 2 Simeulue Timur. Jurnal Ilmiah Didaktika, 14 (2): 390-400.

Suriansyah, Ahmad dan Aslamiah. 2015. Strategi Kepemimpinan kepala sekolah, guru, orangtua, dan masyarakat dalam Membentuk Karakter Siswa. Jurnal Cakrawala Pendidikan. 34 (2).

Sommeng, A. 2018. Peningkatan Kemampuan Guru Dalam Pengembangan Silabus Dan Rpp Melalui Pola Pembinaan Profesional Dengan Pendekatan Kooperatif. JIKAP PGSD: Jurnal Ilmiah Ilmu Kependidikan, 3 (3): 263-273

DOI: http://doi.org/10.26858/jkp.v3i3. $\underline{10230}$ 